\title{
Non-genetic factors affecting fertility traits in South African Holstein cows
}

\author{
C.J.C. Muller ${ }^{1}$, J.P. Potgieter ${ }^{2}$, S.W.P. Cloete ${ }^{1,2}$ \& K. Dzama ${ }^{2}$ \\ ${ }^{1}$ Directorate: Animal Sciences, Research and Technology Development Services, Western Cape Department of \\ Agriculture, Private Bag X1, Elsenburg 7607, South Africa; ${ }^{2}$ Department of Animal Sciences, University of Stellenbosch, \\ Stellenbosch 7600, South Africa
}

(Received 20 November 2013; Accepted 2 February 2014; First published online 8 March 2014)

Copyright resides with the authors in terms of the Creative Commons Attribution 2.5 South African Licence.
See: http://creativecommons.org/licenses/by/2.5/za
Condition of use: The user may copy, distribute, transmit and adapt the work, but must recognise the authors and the South African Journal of
Animal Science.

\begin{abstract}
Profitable milk production and genetic improvement in dairy herds depend largely on fertile cows calving annually to initiate a new lactation period. Over the last 30 years, several studies have indicated a decline in the reproductive performance of dairy cows. From the perspectives of many farmers and veterinarians, the reproductive performance of cows is related to the calving interval $(\mathrm{Cl})$ and services per conception (SPC). Using these traits as cow fertility indicators is problematic as $\mathrm{Cl}$ is dependent on subsequent calving dates, while SPC is strongly linked to inseminator proficiency. Cow fertility refers to the ability of cows to come into oestrus soon after calving, to conceive from a minimum number of services, and to stay pregnant until the next calving. In this paper, non-genetic factors affecting fertility traits other than $\mathrm{Cl}$ in Holstein cows are discussed. Service records $(n=69181)$ and pregnancy check results of 9046 cows in 14 herds were available. Six fertility traits were derived. Means ( \pm sd) for the interval traits, namely calving to first insemination (CFS) and the interval from calving to conception (days open (DO)) were $77 \pm 30$ and 134 \pm 74 days, respectively, while the number of SPC was $2.55 \pm 1.79$. The proportion of first services occurring within 80 days post partum (FS80d) and the proportion of cows being confirmed pregnant within 100 days (PD100d) and 200 days post partum (PD200d) were $0.64 \pm 0.48,0.36 \pm 0.48$ and $0.71 \pm 0.45$, respectively. While lactation number, calving year and calving season affected reproduction traits significantly, herds (management) had the largest effect.
\end{abstract}

Keywords: Dairy cows, days open, interval to first insemination, reproduction

\# Corresponding author: carelm@elsenburg.com

\section{Introduction}

Profitable milk production and genetic improvement in dairy herds depend on fertile cows calving annually to initiate a new lactation period. However, several studies have shown a decline in the reproductive performance of dairy cows (Lucy, 2001; Andersen-Ranberg et al., 2003; Lopez-Gatius, 2003; Veerkamp et al., 2003). In South African Holsteins, the calving interval (Cl) increased from 386 days in 1986 to 412 days in 2004 (Makgahlela, 2008). It seems that selection for higher milk yields has led to a decline in the fertility of dairy cows because of the unfavourable genetic correlation between yield and fertility (Pryce et al., 2004). However, other factors, such as increased herd sizes and less labour input per cow, could have contributed to the decline in fertility. Breeding and selection programmes in South African dairy herds have focused on the improvement of milk yield and conformation traits. While it is well accepted that the reproductive performance of dairy cows affects herd profitability, specifically through the cost of rearing higher numbers of replacement heifers, higher veterinary and insemination costs, as well as extended lactation periods, dairy farmers put little emphasis on the improvement of cow fertility. At best, non-pregnant cows are eventually culled because of reproductive failure. This is done only after considerable effort has been put into getting cows pregnant. This commonly includes a large number of inseminations, fertility hormone treatment sessions and natural service by a home-bred bull. This usually results in a protracted interval from calving to conception, leading to a high $\mathrm{Cl}$.

To improve the fertility of dairy cows, information is required on the genetic merit for fertility. Fertility in dairy cows is a complex trait and is highly linked to the standard of reproduction management. A number of non-genetic factors affect the fertility of dairy cows. Excluding milk yield levels, some of these factors are 
lactation number, calving year, calving season and herd or managerial effects. According to Hillers et al. (1984), third and older lactation cows have lower conception rates and longer intervals to first insemination in comparison with first and second lactation cows. Following parturition, cows must undergo a series of recovery events in addition to returning to normal oestrus cycling (Malven, 1984). Erb et al. (1981) suggested that poor reproductive performance in older cows is because of more frequent occurrences of reproductive diseases such as dystocia, retained placentas, cystic ovaries and metritis. Generally, fertility is better in open heifers than in lactating cows. Pryce et al. (2002) found conception rates of $64 \%$ in open heifers and $39 \%$ in lactating cows with a high milk yield genetic merit. Eicker et al. (1996) showed that conception rate in dairy cows varied with season and parity.

Mostert et al. (2010) reported on genetic parameters for $\mathrm{Cl}$ in the four major South African dairy breeds. Although this is the first step towards the genetic evaluation of the fertility of South African dairy cows, Haile-Mariam \& Goddard (2007) pointed out that while Cl may be used for the genetic evaluation of dairy cow fertility, cows that do not calve again for any reason, including those that are culled for failing to conceive, are generally not included in the genetic evaluation. This means that information about the perceived least fertile group of cows is excluded, possibly leading to inaccurate estimated breeding values of sires for fertility. While the absence of a subsequent calving date does not provide a $\mathrm{Cl}$, some reproductive information could be gathered for cows from service records such as the interval from calving to first service, and whether the first service was within a set period after calving.

Because dairy farmers routinely keep artificial insemination (Al) records and pregnancy test results for herd management, such data could be used in the genetic evaluation of dairy cows for fertility. From this information, specific fertility-related intervals could be estimated as indicators of cow fertility. In Canada, fertility traits have been implemented in the milk recording scheme. Insemination data have been accumulated since 1997, and a national genetic evaluation programme for dairy cow fertility traits has been developed (Jamrozik et al., 2005). Van Doormaal et al. (2004) reported preliminary results for four fertility traits, that is, age at first service in heifers, non-return rate to $56 \mathrm{~d}$ in heifers and cows, and the interval from calving date to first insemination date for Canadian dairy breeds. Jamrozik et al. (2005) concluded that female fertility is a complex set of traits, related through genetic and environmental factors. Some of these traits could be combined in a fertility index.

The aim of the study is to determine the effect of non-genetic factors on reproduction traits other than $\mathrm{Cl}$ towards estimating genetic parameters for fertility traits in South African Holstein cows.

\section{Material and methods}

All Al records ( $n=69$ 181) of cows calving down in the period between 1991 and 2007 in 14 South African Holstein herds were used. Herds consisted of cows in both zero-grazing and pasture-based production systems in the Western, Southern and Eastern Cape and Kwazulu-Natal regions of South Africa. A total of 24646 lactation records from 9046 individual cows were available. The outcome of each Al event was known. Pregnancy diagnosis was based on rectal palpation by a veterinarian, usually on a monthly farm visit. Cows experiencing calving and other problems, such as retained placentas, were treated by a veterinarian as required. Insemination records were linked to the calving date of each cow, lactation number, dam and sire identification numbers. By using this information, fertility traits were derived that measure the ability of cows to show heat early in the breeding period and the probability of the success of insemination and confirmation of pregnancy. These traits included the interval from calving date to first service date (CFS), the interval from calving date to conception date or days open (DO), the number of services per conception (SPC), whether cows were inseminated within 80 days post partum (FS80d), and whether cows became pregnant within 100 days (PD100d) and 200 days post partum (PD200d). Non-interval traits were recorded as binary threshold traits coded as $1=$ no and $2=$ yes. The calendar year was divided into four seasons, that is, January to March, April to June, July to September and October to December as seasons 1, 2, 3 and 4, respectively. Reproduction records exceeding four standard deviations from the mean for each trait were deleted from the data set during editing.

To determine which fixed effects should be included in the model, an analysis was carried out using the general linear model (PROC GLM) procedure of GenStat Seventh Edition software (Lawes Agricultural Trust, 2007). The REML linear mixed model (LMM) procedure was implemented for continuous traits and the generalized linear mixed model (GLMM) procedure was used for binomial traits via a LOGIT link back transformation. Significant $(P<0.05)$ fixed effects that were subsequently incorporated into the final model for genetic analysis were herd (14 levels), year of calving (17 levels), season of calving (4 levels) and lactation number (6 levels). The GLMM models included herd as a random factor (De Vries \& Risco, 2005). Least square mean estimates and REML solutions for the significant fixed effects were also derived. 


\section{Results and Discussion}

Descriptive statistics for fertility traits evaluated in this study are presented in Table 1. Cows eventually became pregnant in most lactation periods $(0.85 \pm 0.36)$. Although average values for some traits were acceptable from a management point of view, a large variation was observed, as indicated by high standard deviations. This is to be expected as the observed values for these traits are the result of a complex interplay among elements such as the decision policy of the dairy farmer for the voluntary waiting period (VWP), postcalving treatment of cows, nutritional management, environmental factors and the genetic merit of cows for fertility. The coefficients of variation for the interval traits were 0.39 and 0.70 for CFS and SPC, respectively. The mean \pm standard deviation (SD) interval from CFS was $77 \pm 30$ days with only $64 \%$ of first services occurring within 80 days post partum. The interval DO was high and variable at $134 \pm 74$ days. Only in $36 \%$ and $71 \%$ of all lactations were cows confirmed pregnant within 100 and 200 days post partum, respectively.

Table 1 Descriptive statistics for raw data analysed for fertility traits, that is, interval from calving date to first service date (CFS), days open interval (DO), number of services per conception (SPC), whether cows were inseminated for the first time within 80 days post partum (FS80d), whether cows were confirmed pregnant within 100 days post partum (PD100d) and whether cows were confirmed pregnant within 200 days post partum (PD200d)

\begin{tabular}{|c|c|c|c|c|c|c|}
\hline \multirow{2}{*}{ Variables } & \multicolumn{6}{|c|}{ Fertility traits } \\
\hline & CFS (days) & DO (days) & SPC & FS80d & PD100d & PD200d \\
\hline Number of records & 16605 & 14255 & 14255 & 16648 & 16648 & 16648 \\
\hline Mean & 77.3 & 133.9 & 2.55 & 0.64 & 0.36 & 0.71 \\
\hline Standard deviation & 29.9 & 74.3 & 1.79 & 0.48 & 0.48 & 0.45 \\
\hline CV (\%) & 38.7 & 55.5 & 70.2 & 75.2 & 133.7 & 64.0 \\
\hline Minimum & 21 & 21 & 1 & 1 & 1 & 1 \\
\hline Maximum & 250 & 435 & 8 & 2 & 2 & 2 \\
\hline
\end{tabular}

CV: coefficient of variation.

Early first insemination after calving and a high first insemination success rate would reduce $\mathrm{Cl}$. The study showed that while in $64 \%$ of lactations first service was done within 80 days of calving, a considerable number occurred much later. In addition, first Al success rate was poor, at less than $40 \%$. Furthermore, because of poor heat detection and service inefficiency, this resulted in an extended interval from first service to conception, resulting in a high number of DO. Only 36\% of DO intervals were concluded within 100 days post calving, while $29 \%$ dragged on for longer than 200 days after calving. This is reflected in the relatively large number of services per conception (SPC) of $2.55 \pm 1.79$ observed in this study. This indicates a less-than-average insemination efficiency of 0.39. Haile-Mariam et al. (2004) reported a lower SPC of 1.85 in Australian dairy herds. The reason for extended intervals from calving to first service could be ascribed to the reproductive management of cows after calving, that is, cows with uterine infections or reproductive problems such as cystic ovaries that were not observed early. Uterine infections could be caused by the calving environment, that is, wet and dirty conditions, the birth weight of calves (poor sire selection), presentation (position) of calves during the birth process, retained placentas because of nutritional imbalances, and a host of other potential causes.

The effects of herd, year of calving, season of calving and lactation number on fertility traits are presented in Table 2. Herd had the largest effect on variation for all fertility traits evaluated in this study, with the exception of DO. This is probably because of management factors related to the calving process, VWP, heat detection rate and inseminator proficiency.

The effects of herd and calving year on the interval traits CFS and DO are presented in Figure 1. Large differences were found between herds. That is, minimum and maximum intervals were 75 and 142 days for CFS and 115 and 185 days for DO, respectively. The increase in the CFS and DO intervals followed a quadratic trend, $\mathrm{R}^{2}=0.39$ and $\mathrm{R}^{2}=0.74$, respectively, over time. The largest increase in CFS occurred from 1991 to 1994 , when the annual increase was 3.5 days $\left(R^{2}=0.75 ; P<0.05\right)$. From 1995 , the interval CFS did not change over time, probably indicating that herd managers were not able to improve this trait or that managers had accepted this level of reproductive performance. De Vries \& Risco (2005) also showed 
that the number of days from calving date to first service date for Holstein cows in the USA increased from 84 in 1983 to 104 days in 2001. In the present study, overall, the average number of days from calving to conception increased from 127 days in 1991 to 153 days in 2006. For DO the largest increase occurred $(P$ $<0.10$ ) from 1991 to 1998 at 2.1 days per year, while from 1998 onwards there was no change in the DO interval. These results suggest that farmers have adopted a specific strategy regarding the VWP and insemination protocols to maintain a DO interval of about 147 days. The largest $(P<0.001)$ difference in DO was between herds 11 and 13 , being $77.8 \pm 6.8$ days. Washburn et al. (2002) accordingly found that the number of DO increased from about 126 days in 1976 to 169 days in 1999 in Holstein and Jersey herds in the USA.

Table 2 Estimated least square means of the effect of herd, calving year, calving season and lactation number on fertility traits in South African Holstein cows (CFS = interval from calving to first service; FS80d = proportion of cows inseminated within 80 days post partum, PD100 $d=$ proportion of cows confirmed pregnant with $100 \mathrm{~d}$ post partum, PD200 d = proportion of animals confirmed pregnant within 200 days post partum)

\begin{tabular}{lcccc}
\hline & \multicolumn{4}{c}{ Fixed effects } \\
\cline { 2 - 5 } Traits & Herd & $\begin{array}{c}\text { Calving } \\
\text { year }\end{array}$ & $\begin{array}{c}\text { Calving season } \\
\text { Lactation } \\
\text { number }\end{array}$ \\
\hline Degrees of freedom & 13 & 16 & 4 & 5 \\
CFS & $2598201^{\star \star}$ & $118646^{\star \star}$ & $25816^{\star \star}$ & $75173^{\star \star}$ \\
Days open & $1259070^{\star \star}$ & $2273999^{\star \star}$ & $21501^{1}$ & $331422^{\star \star}$ \\
Services per conception & $1473.7^{\star \star}$ & $1059.9^{\star \star}$ & $27.9^{1}$ & $34.1^{1}$ \\
FS80d & $487.6^{\star \star}$ & $41.4^{\star \star}$ & $6.1^{\star \star}$ & $11.8^{\star \star}$ \\
PD100d & $119.7^{\star \star}$ & $25.4^{\star \star}$ & $9.2^{\star \star}$ & $14.7^{\star \star}$ \\
PD200d & $196.9^{\star \star}$ & $37.3^{\star \star}$ & $7.5^{\star \star}$ & $32.3^{\star \star}$ \\
\hline
\end{tabular}

${ }^{\star \star} P<0.01 ;{ }^{\star} P<0.05 ;{ }^{1}$ Not significant.

Extended DO intervals could be the result of a consious decision to postpone the first insemination after calving, possibly to save on insemination costs. This resulted in extended lactations, however, causing a loss in milk income, especially for cows with a low milk yield persistency towards the end of the lactation. Extended lactations with poor milk yield persistency result in reduced milk yield (Muller, 2011). The interval from calving to first service and DO intervals were both affected $(P<0.05)$ by parity, although differences were small. The average number of days for CFS decreased from $83.7 \pm 0.5$ to $78.5 \pm 0.6$ days from parity 1 to parity 3. This trend is in agreement with Berry et al. (2011), who reported that the average interval for CFS for parity 1 to 5 was $79,77,75,75$ and 74 days, respectively, for Irish commercial dairy herds. The reason for the observed longer CFS for first parity cows is not clear. However, the physiological stress of first calving could affect their reproductive performance, while cows continue to grow during their first pregnancy, therefore having to partition dietary energy intake between maintenance, growth, lactation and reproduction. Contrary to this, average DO for cows increased $(P<0.05)$ from first to sixth lactation, that is, from $136 \pm 2$ to $145 \pm 4$ days. Differences in DO between parities 1 and 4 were small, $1.5 \pm 0.6$ days, while from parity 4 to 6 DO increased with $3.9 \pm 1.8$ days per parity. A possible explanation for this trend could be failure to detect early heat signs after calving or managers delaying first service to facilitate a positive outcome. This allows more insemination opportunities for older, usually higher-yielding cows to conceive.

Season of calving affected $(P<0.001)$ CFS intervals, although differences between seasons were small, that is, $79.4 \pm 0.6$ and $82.4 \pm 0.7$ days for cows calving from January to June and calving from July to December, respectively. Although DO intervals were affected by season $(P<0.05)$, differences for DO intervals were small, that is, $136.6 \pm 1.9$ days for the April to June season versus $142.3 \pm 2.0$ days for the October to December calving season. This could be ascribed to the rainfall pattern, because most herds used in the study were in the summer rainfall area of South Africa. This means that cows calving down from October to December had to endure wet conditions. This could cause an increase in metritis problems because of a dirty calving environment. Carmona Solano \& Sato Vargas (1987) and Mangurkar et al. (1985), also reported that season and production year affected $(P<0.01)$ the DO interval of Holsteins in Costa Rica and Friesians and Jerseys in India, respectively. 
a)

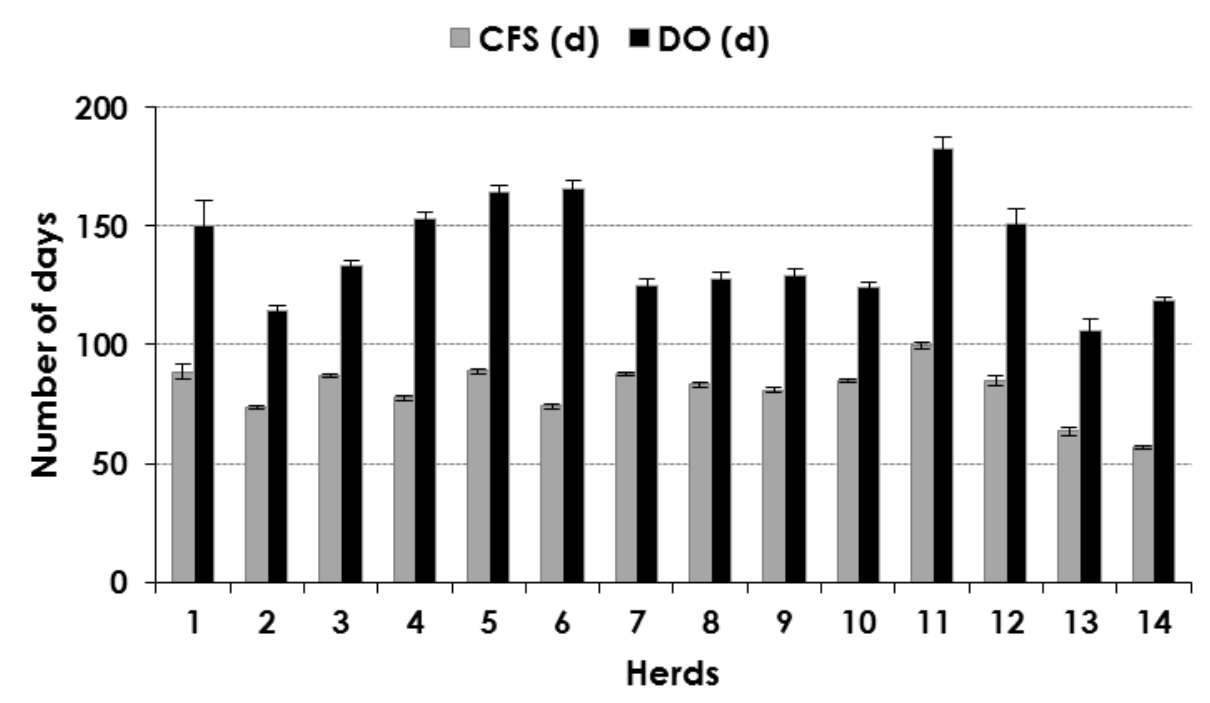

b)

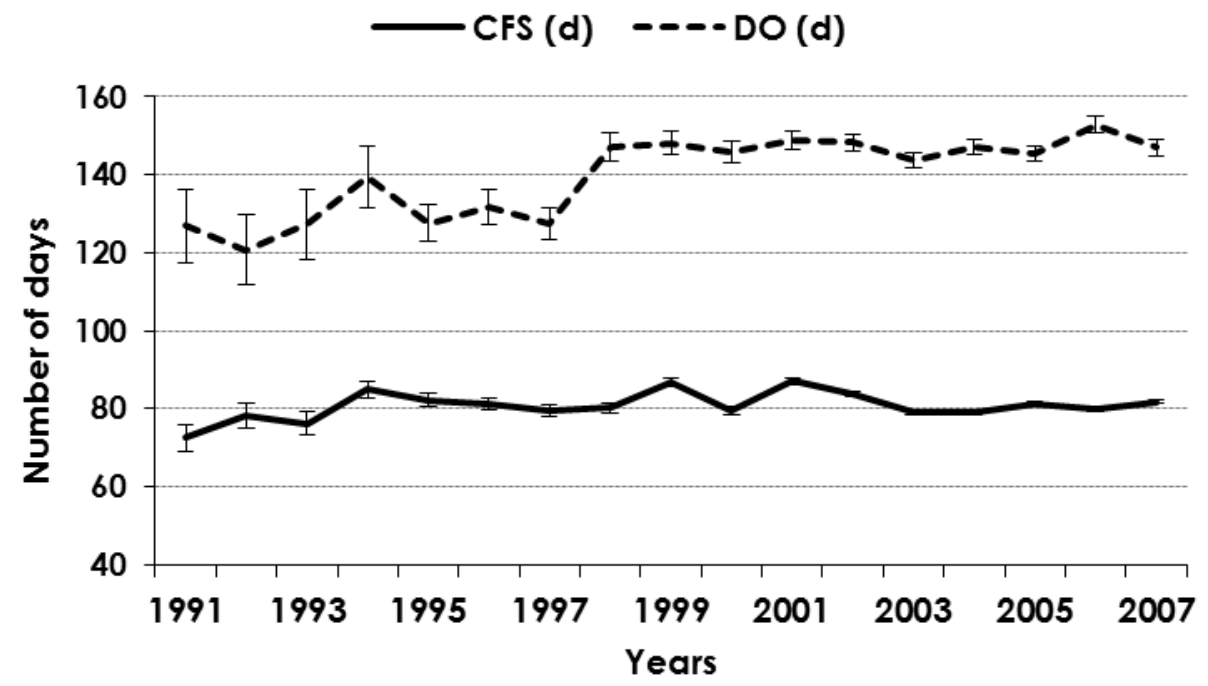

Figure 1 Effect of a) herd and b) calving year on interval traits for calving date to first service date (CFS) and days open (DO).

Asimwe \& Kifaro (2007) found that crossbred Friesian cows in smallholder production systems in Tanzania that had calved from 1985 to 1990 had the longest DO (224 days), while those that calved from 1995 onwards had the shortest DO (159 days), probably reflecting an improvement in reproductive management by farmers. Asimwe \& Kifaro (2007) also suggested that feeding poor-quality feed during the dry periods resulted in longer DO intervals because of a longer recovery period after calving. Delaying first service after calving to save on the cost of semen could result in more cows in the herd being in late lactation, when milk yield is naturally lower, resulting in a larger loss in milk income than in insemination cost.

The effect of herd and production year on the number of services per conception (SPC) is presented in Figure 2. Large differences were observed among herds. That is, minimum to maximum values for Herds 7 and 6 were 1.9 and 3.3 SPC, respectively. For production year, a linear trend $(P<0.01)$ was observed from 1992 to 2006, with the average number of SPC increasing from $2.1 \pm 0.2$ to $2.9 \pm 0.1$. Specifically, from 1998 onwards the insemination efficiency was below $40 \%$. Furthermore, the number of SPC increased linearly ( $P$ $<0.01$ ) with increasing lactation number. This could be related to increasing milk yield levels for older cows. The number of services per conception was lower in the cooler months of the year, that is, from April to 
September, with the higher number of services per conception observed in the summer, that is, from October to March.

a)

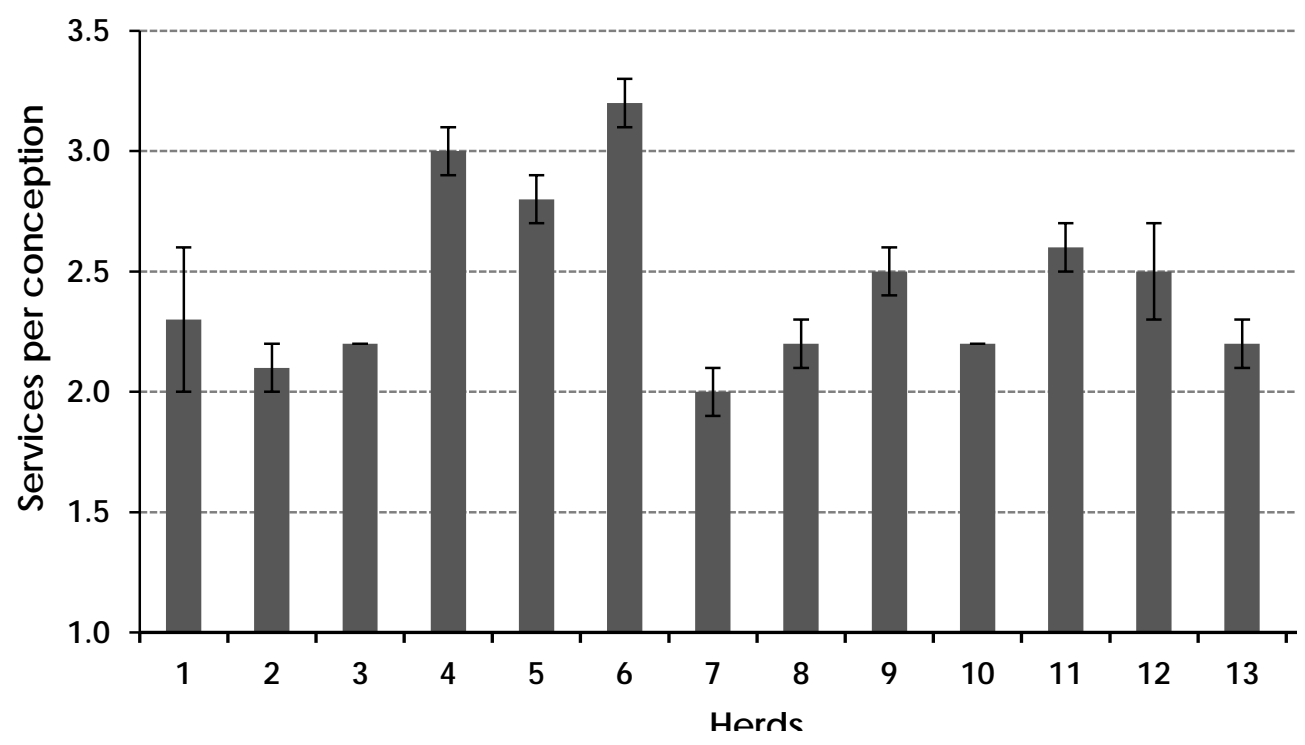

b)

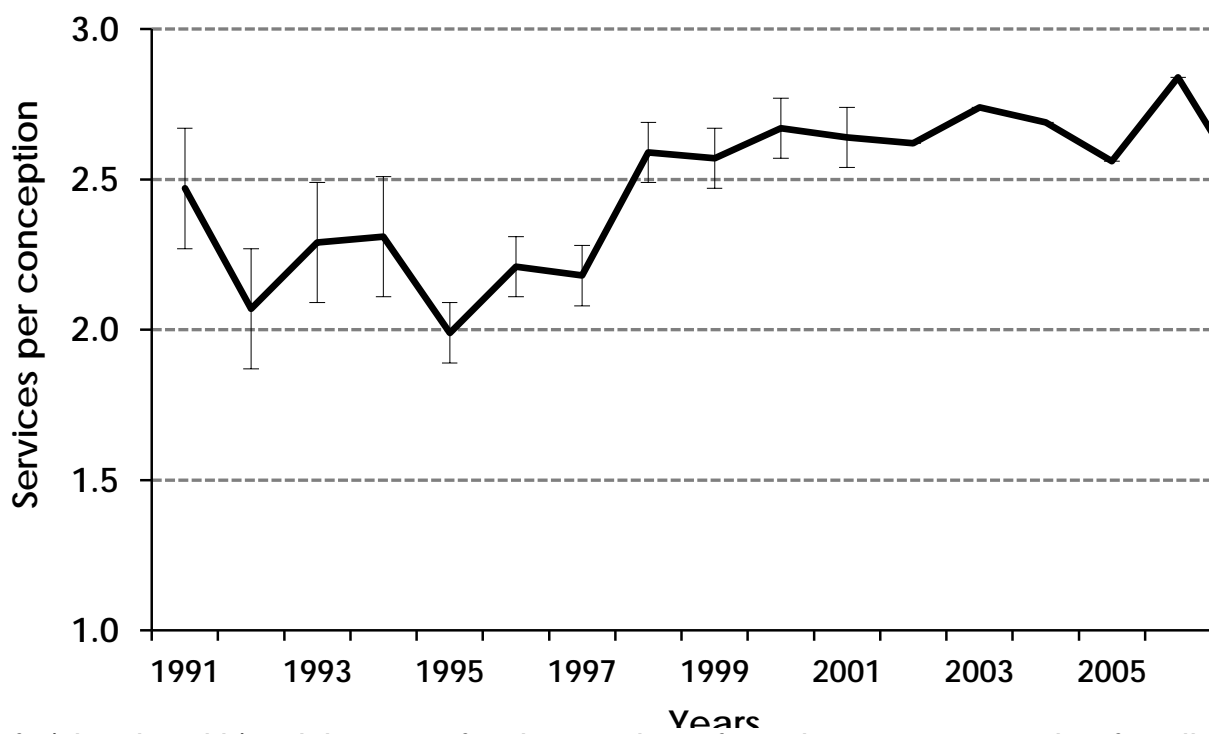

Figure 2 Effect of a) herd and b) calving year for the number of services per conception for all cows in 14 Holstein herds.

According to an Australian survey (Little, 2003), an average SPC above 2.32 indicates herd reproductive problems. SPC was higher than 2.3 in seven of the 14 herds surveyed in the present study. Jamrozik et al. (2005) found that SPC \pm SD for first parity and older Holstein cows in Canada was $1.64 \pm$ 1.09 and $2.14 \pm 1.50$, respectively. In that analysis a value of 10 was used for SPC values higher than 10 . This would reduce mean SPC values, thereby showing a better reproductive performance by dairy farmers. A survey of 19 Holstein-Friesian dairy herds in Ireland (Mackey et al., 2007) showed that fertility performance was generally poor, with the interval to first service being $84.4 \pm 35.4$ days, and first insemination success rate amounting to $40.6 \pm 0.68 \%$. The 100-day in-calf rate was $46.0 \pm 0.68 \%$ and $\mathrm{Cl} 404 \pm 65$ days. By backcalculation, that is, the difference between $\mathrm{Cl}$ and gestation length (González-Recio et al., 2006), the number of DO could be calculated. For a $\mathrm{Cl}$ of 404 days, DO would be ca. 124 days, which is slightly lower than the mean of $134 \pm 74$ days observed in the present study. Mackey et al. (2007) also noted that the major cause of poor reproductive performance in Irish dairy herds was the prolonged interval to first service and the poor 
success rate at first Al. The result of this is that only $46 \%$ of cows were confirmed pregnant by 100 days in milk, although this varied considerably between herds, that is, $16.4 \%$ to $70.8 \%$. In the present study first Al success rate varied from $24 \%$ to $50 \%$ between herds. Other researchers (Grosshans et al., 1997; Royal et al., 2000) found first Al success rates of $39.7 \%$ and $48.5 \%$ in seasonal New Zealand and United Kingdom Holstein cows, respectively.

Overall, the percentage of cows that were inseminated for the first time within 80 days post partum (FS80d) differed $(P<0.05)$ between herds, being $64 \%$ on average (Figure 3$)$. For Herds 11 and 14, the number of $\mathrm{FS}<80 \mathrm{~d}$ was $39 \%$ and $93 \%$, respectively, indicating substantial management differences between these two herds. Over the production years evaluated, the percentage of cows inseminated within 80 days of calving, although varying between years, followed a quadratic downward trend $\left(R^{2}=0.49\right)$ from $77 \%$ in 1991 to $56 \%$ in 2007 . This indicates that over time fewer heats were observed or that fewer cows were showing heat in the early stages of the lactation period. This could reflect poor detection techniques (a management problem) or declining fertility in dairy cows because of their genetic merit for fertility. The percentage of cows serviced within 80 days post partum increased by parity, that is, from $56 \%$ for first parity cows to $62 \%$ for third and fourth parity cows. The effect of parity on FS80d was described by a polynomial regression equation $\left(y=51.673+5.927 x-0.831 x^{2} ; R^{2}=0.90\right)$. However, actual values varied little for cows in different parities.

a)

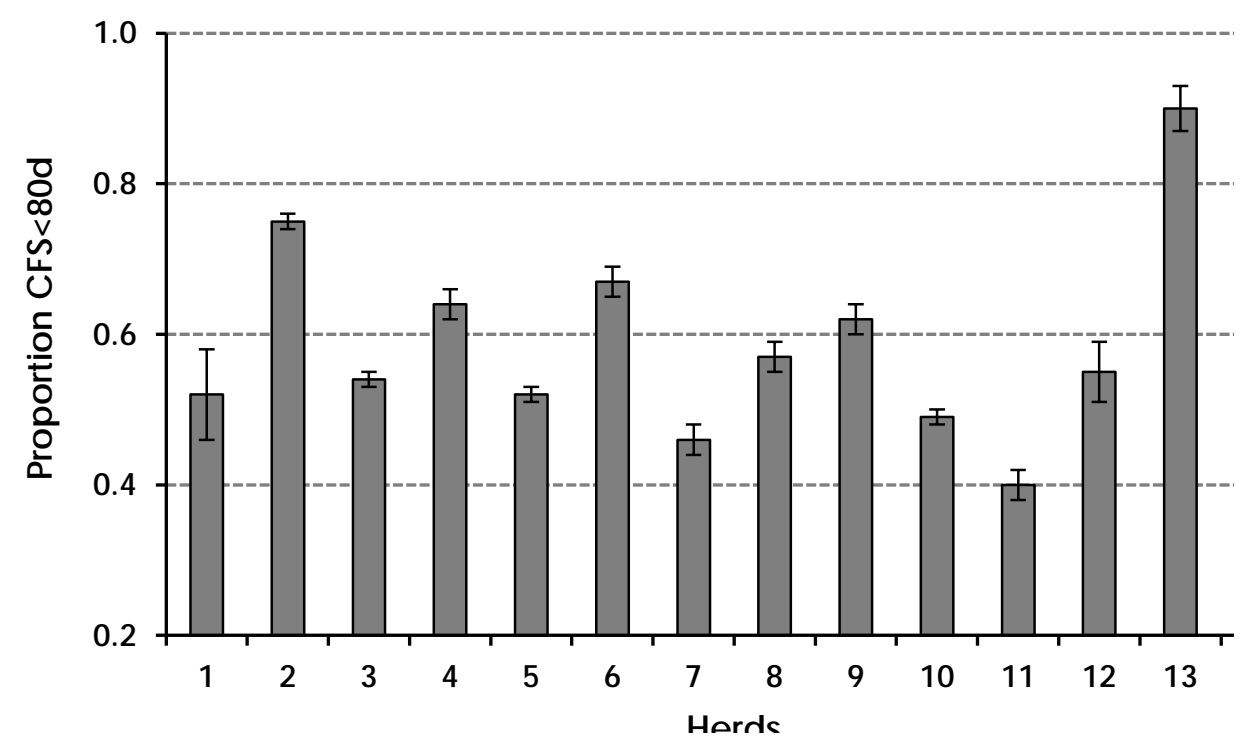

b)

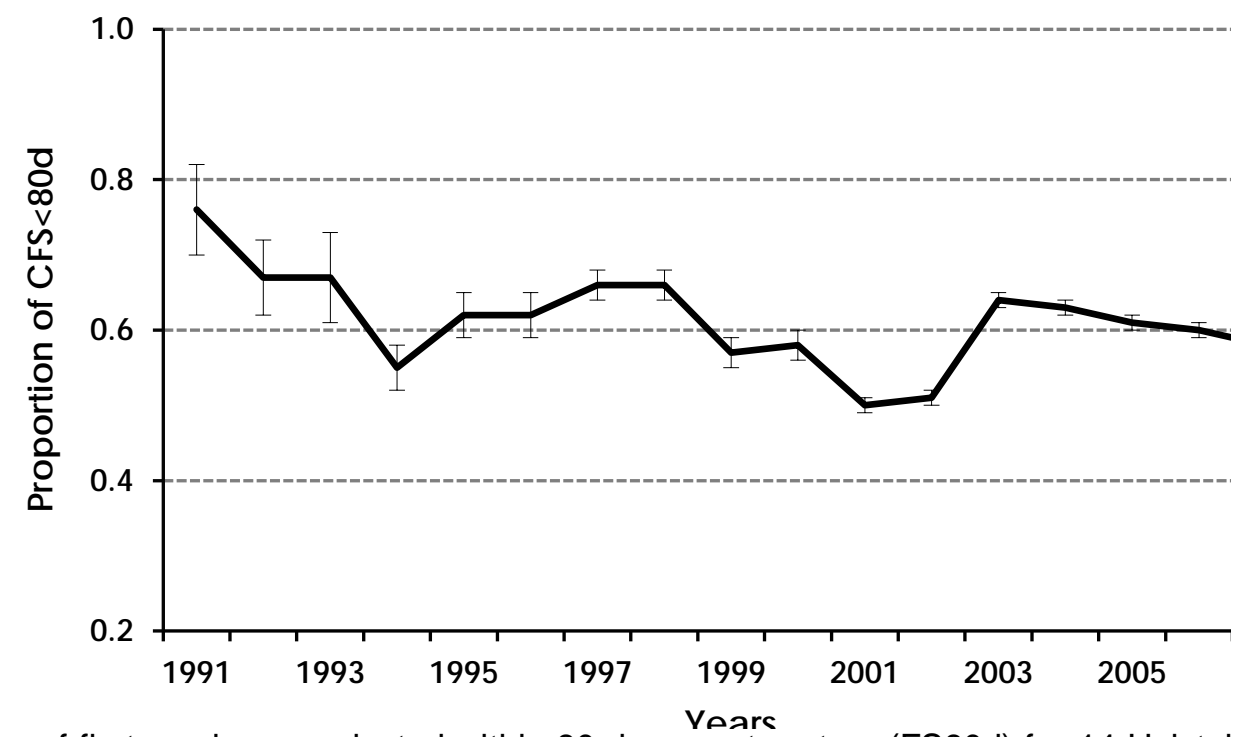

Figure 3 Proportion of first services conducted within 80 days post partum (FS80d) for 14 Holstein herds a) and for years from 1991 to 2007 b). 
This is nonetheless a positive result because of the general perception that older cows, usually producing more milk, would be prone to show first oestrus later after calving. This study does not support that perception. While calving season affected FS80d $(P<0.01)$, differences between seasons were small, with minimum and maximum values of $52 \%$ and $58 \%$ respectively, with higher values observed in January to March. It was expected that fewer cows would show early first inseminations in the summer months because of the general perception that cows experience poor fertility during time of the year where higher temperatures are experienced.

a)

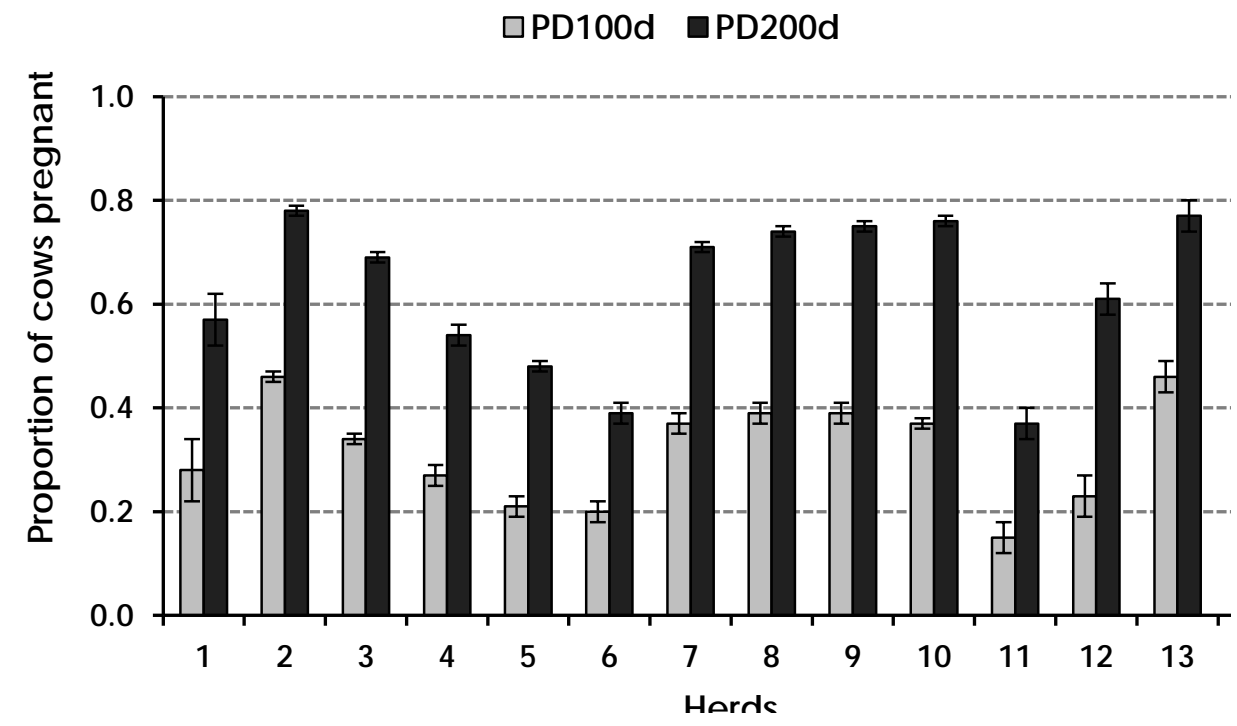

b)

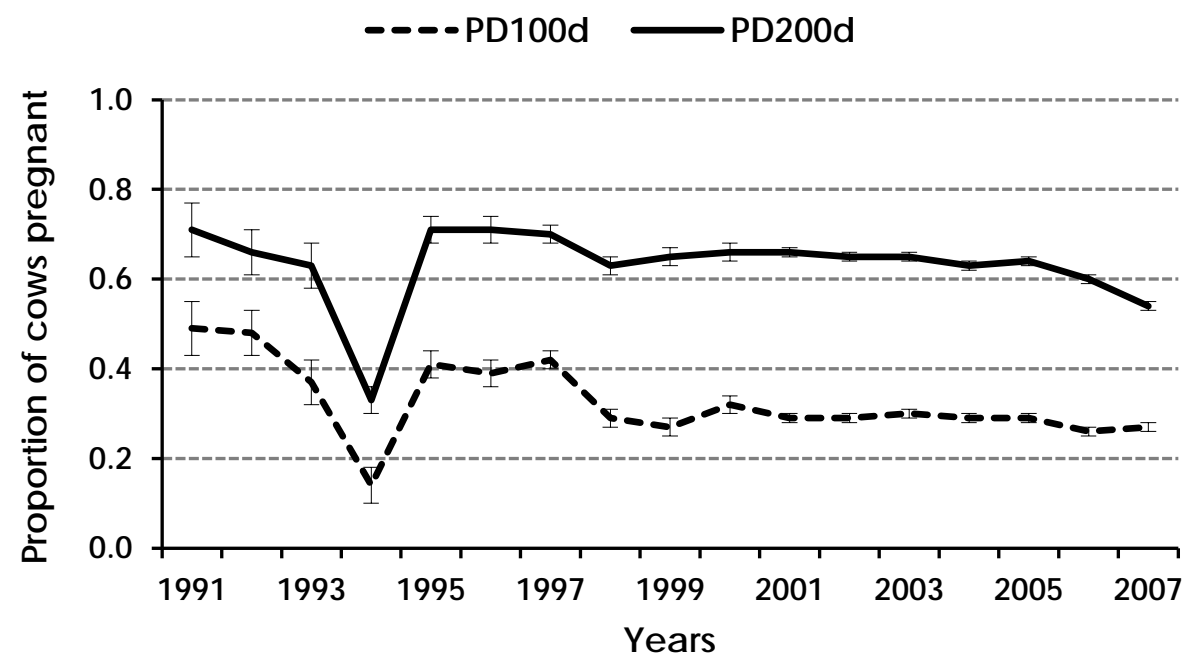

Figure 4 Effect of a) herd and b) production year on the proportion of cows confirmed pregnant within 100 days (PD100d) and 200 days (PD200d) post partum for 14 Holstein herds.

When studying four Spanish dairy herds, Lopez-Gatius (2003) found that the number of heat cycles and SPC were lower and higher $(P<0.05)$, respectively, in the warmer summer months than in the cooler winter months. Some dairy producers deliberately do not breed cows during parts of the summer (Washburn et al., 2002; Oseni et al., 2003). Jordan (2003) found that fertility of dairy cows is reduced under heat stress conditions during hot summer months. Delayed breeding may be economically advantageous (Gröhn \& Rajala-Schultz, 2000; Arbel et al., 2001). The effect of season on the result of services was not tested in the current study. 
The percentage of cows confirmed pregnant within 100 and 200 days post partum, as affected by herd and year of calving is presented in Figure 4. On average, the percentage of cows confirmed pregnant by 100 and 200 days post partum was $36 \%$ and $71 \%$, respectively. Relatively large differences were observed between herds, that is, the minimum and maximum values were $14 \%$ and $45 \%$ for PD100d and $38 \%$ and $75 \%$ for PD200d, respectively. Even at the higher end (indicating better managers for this group of herds), observed results were lower than those found in the Australian survey for the establishment of the InCalf Project (Little, 2003). Part of the differences between herds could be ascribed to deliberate changes in reproductive management. Increased conception rates with an increased VWP past 70 days (Britt, 1985) could encourage farmers to start inseminating cows later.

While the percentage of cows confirmed pregnant within 100 days post partum decreased $(P<0.05)$ from $44 \%$ in 1991 to $27 \%$ in 2007 , this was not observed for cows 200 days post partum. Numerically fewer cows were confirmed pregnant by 200 days post partum in 2007 in comparison with 1991, that is, $55 \%$ vs. $68 \%$. The linear trend for this trait was not significant $(P>0.05)$, probably because of large variation between years. The unexpectedly low value for PD100d in 1994 for cows was probably owing to a smaller number of animals with records in the dataset for that specific year.

The percentage of cows confirmed pregnant within 100 and 200 days post partum showed a curvilinear downward trend $(P<0.01)$ from parity one to parity six. The reduction in the percentage of cows confirmed pregnant was relatively small from the first to fourth parity in comparison with the reduction to sixth parity.

The percentage of cows confirmed pregnant within 100 and 200 days post partum differed between seasons of calving. Cows that calved from January to September showed higher percentages of pregnancy 100 days post partum than cows that calved from October to December. According to Washburn et al. (2002) and Oseni et al. (2003) a number of US dairy farmers deliberately do not breed cows during parts of the summer to prevent a reduction in pregnancy rate. There is no evidence that local farmers use a similar practice.

\section{Conclusion}

This study provides a preliminary indication of the standard of reproduction management in South African Holstein herds. Reproduction traits were affected significantly by all the fixed effects considered, with herd (presumably an indicator of managerial and inseminator skills) exerting the largest effect. Interval traits showed an increase over time, although reaching a plateau of 80 days for the interval CFS and 140 days for $\mathrm{DO}$, probably indicating a large management effect on these traits. The effect of season on the success rate of inseminations should be studied further once more data have been accrued. It is evident that the fixed effects considered should mostly be included in analyses aimed at estimating genetic parameters for these fertility traits to ensure unbiased parameters.

\section{References}

Andersen-Ranberg, I.M., Heringstad, B. Klemetsdal, G., Svendsen, M. \& Steine, T., 2003. Heifer fertility in Norwegian dairy cattle: Variance components and genetic change. J. Dairy Sci. 86, 2706-2714.

Arbel, R., Bigun, Y., Ezra, E., Sturman, H. \& Hojman, D., 2001. The effect of extended calving intervals in high-yielding lactating cows on milk production and profitability. J. Dairy Sci. 84, 600-608.

Asimwe, L. \& Kifaro, G.C., 2007. Effect of breed, season, year and parity on reproductive performance of dairy cattle under smallholder production system in Bukoba district, Tanzania. Livest. Research for Rural Devel. 19 (10), article \#152. Accessed February 3, 2014, from htm://www.Irrd.org//rrd19/10/asim19152.htm.

Berry, D.P., Evans, R.D. \& McParland, S., 2011. Evaluation of bull fertility in dairy and beef cattle using cow field data. Theriogenology $75,172-181$.

Britt, J.H., 1985. Enhanced reproduction and its economic implications. J. Dairy Sci. 68, 1585-1592.

Carmona Solano, G.A. \& Sato Vargas, O.M., 1987. Analysis of production and reproductive performance in a dual-purpose and a specialized dairy herd. Ciencias Veterinarias, Costa Rica. 9, 141-147.

De Vries, A. \& Risco, C.A., 2005. Trends and seasonality of reproductive performance in Florida and Georgia dairy herds from 1976 to 2002. J. Dairy Sci. 88, 3155-3165.

Eicher, S.W., Gröhn, Y.T. \& Hertl, J.A., 1996. The association between cumulative milk yield, days open and days to first breeding in New York Holstein cows. J. Dairy Sci. 79, 235-241.

Erb, H.N., Martin, S.W., Ison, N. \& Swaminathan, S., 1981. Interrelationships between production and reproductive diseases in Holstein cows. Conditional relationships between production and disease. J. Dairy Sci. 64, 272-281.

González-Recio, O., Chang, Y.M., Gianola, D. \& Weigel, K.A., 2006. Comparison of models using different censoring scenarios for days open in Spanish Holstein cows. Anim. Sci. 82, 233-239. 
Gröhn, Y.T. \& Rajala-Schultz, P.J., 2000. Epidemiology of reproductive performance in dairy cows. Anim. Reprod. Sci. 60/61, 605-614.

Grosshans, T., Xu, Z.Z., Burton, L.J., Johnson, D.L. \& Macmillan, K.L., 1997. Performance and genetic parameters for fertility of seasonal dairy cows in New Zealand. Livest. Prod. Sci. 51, 41-51.

Haile-Mariam, M. \& Goddard, M.E., 2007. An alternative measure of fertility for genetic evaluation of dairy cattle. Proc. Adv. Anim. Breed. Gen. 17, 445-448.

Haile-Mariam, M., Bowman, P.J. \& Goddard, M.E., 2004. Genetic and environmental relationship among calving interval, survival, persistency of milk yield and somatic cell count in dairy cattle. Anim. Sci. 80, 189-200.

Hillers, J.K., Senger, P.L., Darlington, R.L. \& Flemming, W.N., 1984. Effects of production, season, age of cows, days dry and days in milk on conception to first service in large commercial dairy herds. J. Dairy Sci. 67, 861-867.

Jamrozik, J., Fatehi, J., Kistemaker, G.J. \& Schaeffer, L.R., 2005. Estimates of genetic parameters for Canadian Holstein female reproduction traits. J. Dairy Sci. 88, 2199-2208.

Jordan, E.R., 2003. Effects of heat stress on reproduction. J. Dairy Sci. 86: (E. Suppl.), E104-114.

Lawes Agricultural Trust, 2007. GENSTAT Version 7. Reference Manual. Claredon Press.

Little, S., 2003. The InCalf Book for dairy farmers. Dairy Australia.

Lopez-Gatius, F., 2003. Is fertility declining in dairy cattle? A retrospective study in northeastern Spain. Theriogenology. 60, 89-99.

Lucy, M.C., 2001. Reproductive loss in high-producing dairy cattle: where will it end? J. Dairy Sci. 84, 1277-1293.

Mackey, D.R., Gordon, A.W., McCoy, M.A., Verner, M. \& Mayne, C.S., 2007. Associations between genetic merit for milk production and animal parameters and the fertility performance of dairy cows. Animal 1 , 29-43.

Makgahlela, L., 2008. Calving interval now included in the national genetic evaluation. National Milk Recording and Improvement Scheme, South Africa. Newsletter No 13, p. 20.

Malven, P.V., 1984. Pathophysiology of the puerperium: definition of the problem. Proc. $10^{\text {th }}$ Intern. Con. Animal Reproduction and Artificial Insemination. University of Illinois, Urbana-Champaign, USA. June 10-14, 1984. Abstract 027. p. III-1.

Mangurkar, B.R., Gokhale, S.B., Shidey, D.N., Pande, A.B. \& Phadris, Y.P., 1985. Reproduction performance and productive performance of Friesian and Jersey purebred cows in a herd in India. J. Dairy Sci. 55, 893-897.

Mostert, B.E., Van der Westhuizen, R.R. \& Theron, H., 2010. Calving interval genetic parameters and trends for dairy breeds in South Africa. S. Afr. J. Anim. Sci. 40, 156-162.

Muller, C.J.C., 2011. The milk yield of dairy cows as affected by calving interval and persistency. National Milk Recording and Improvement Scheme, South Africa. Newsletter no. 16. November 2011. pp. 29-30.

Oseni, S., Misztal, I., Tsuruta, S. \& Rekaya, R., 2003. Seasonality of days open in US Holsteins. J. Dairy Sci. 86, 3718-3725.

Royal, M.D., Darwash, A.O., Flint, A.P.F., Webb, R., Woolliams, J.A. \& Lamming, G.E., 2000. Declining fertility in dairy cattle: changes in traditional and endocrine parameters of fertility. Anim. Sci. 70, 487-501.

Pryce, J.E., Simm, G. \& Robinson, J., 2002. Effects of selection for production and maternal diet on maiden heifer fertility. Anim. Sci. 74, 415-421.

Pryce, J.E., Royal, M.D., Garnsworthy, P.C. \& Mao, I.L., 2004. Fertility in high-producing dairy cows. Livest. Prod. Sci., 86, 125-135.

Van Doormaal, B.J., Kistemaker, G., Fatchi, J., Miglior, F., Jamrozik, J. \& Schaeffer, L.R., 2004. Genetic evaluation of female fertility in Canadian dairy breeds. Interbull Bull. 32, 86-89.

Veerkamp, R.F., Beerda, B. \& Van der Lende, T., 2003. Effects of genetic selection for milk yield on energy balance, levels of hormones, and metabolites in lactating cattle and possible links to reduced fertility. Livest. Prod. Sci. 83, 257-275.

Washburn, S.P., Silvia, W.J., Brown, C.H., McDaniel, B.T. \& McAllister, A.J., 2002. Trends in reproductive performance in southeastern Holstein and Jersey DHI herds. J. Dairy Sci. 74, 244-251. 